\title{
Doing collaborative deconstruction as an 'exorbitant' strategy in qualitative research
}

\author{
Hillevi Lenz Taguchi \\ Stockholm University
}

\begin{abstract}
This paper aims to challenge qualitative research from within our own spaces and practices, by putting to work deconstruction as an 'exorbitant' and collaborative methodological strategy. During a seven month period, PhD students used their research-data aiming at doing deconstruction as collaborative processes of writing and talking, rather than treating deconstruction as an object of philosophical study or applying theory to practice. The process was constituted by a turning, bending and twisting of your own analysis, questioning it and trying to displace the meanings of it: in order to identify how and why you do the analysis you do, and foremost, what other analysis might be possible. A piece of interview-data featuring a six-year-old boy is used as an example. A strong desire among the participants was to do better justice to our data using this strategy. The (im)possibilities of doing justice in deconstructive analysis are thus discussed.
\end{abstract}

\section{Introduction}

This paper is written partly as a response to Julianne Cheek's (2007) call for a necessary 'hesitation' in relation to how we work and position ourselves within our specific space of doing qualitative research, in order not to get 'worked over' by what is presently happening in these spaces (p. 1052). In universities all around the world, demands are raised from central authorities of attaining increased certainty of research outputs and measures. Hence, Cheek challenges us to be engaged in an important academic activism that is critically engaged in discussing and contesting both new and mutated 'old' evidence-based methodologies (p. 1058). Instead of being 'worked over' by what is pushed down on us, we need to ask ourselves how we work within and on theses spaces, she writes (p. 1057). Cheek's call for a necessary activism in qualitative research has encouraged me to write from my own experiences of a kind of activism which might challenge qualitative methodologies from within. By putting to work deconstruction as an 'exorbitant' collaborative methodological strategy we wanted to know if it was possible to do better 'justice' to the multiplicities in our data by using this strategy. Deconstructive analyses have become a growing field of research in the social sciences and education during the last 20 years, although remaining on the margins. Deconstructive analysis then is nothing new. What is however new in this paper are the collaborative processes, specifically addressing post-graduate education. The aim of this paper is thus to show how I, together with ten PhD students, put to work a collaborative process of doing deconstruction on our own data and how we investigated the possibilities of doing better justice to the multiplicity of our data in our analyses produced during this process.

In the section below I will sketch the background to this $\mathrm{PhD}$ work-shop and the ideas it was designed around. In the section that follows, I provide a discussion on how it is possible to understand deconstruction as a methodological strategy, without submitting to the taken-for-granted idea of what a research method is and should be. In the third section of the paper I discuss the ethics of the collaborativeness of this process, relating it to Elam's (1994) writing on feminism and deconstruction as ethical activism and groundless solidarity. The fourth section of the paper provides an example of 
this work, using an excerpt from interview-data with a six-year-old boy in a pre-school class. I will conclude the paper by discussing what it might mean to 'do justice' to qualitative research data in the kind of processes we put to work.

\section{A group of discursively inscribed researchers doing deconstruction on each other's data}

A few years ago I was engaged in postgraduate teaching at the Institute of Education at Stockholm University, Sweden. PhD students started to pose very legitimate questions in relation to analysis of qualitative data, such as: Why it that we as qualitative researchers often get stuck in dominant discursive positionings when analysing our data, as if we were unaware of other possible ways of understanding it? What kinds of knowledge does a specific kind of methodology produce? Why is it that we often fail to recognize that our analyses rely on specific meanings and presuppositions that make it impossible for us to escape productions of power in our analysis? The students asked if it was possible to do better 'justice' to the many complexities embedded in qualitative data and thus the many possible readings that might be possible to do from the same data.

To explore these questions, I designed a part-time work-shop in two parts, with a group of fourteen $\mathrm{PhD}$ students during the period of November 2005 and June 2006. The main idea of this work-shop was to collaboratively engage in deconstructive analysis of the participating PhD student's and my own data, with two aims. ' The overriding aim was to produce 'better' analysis for our research. However, it was also made explicit that I had a research interest in investigating what deconstruction might mean and become in the process of putting it to work as a collaborative process. The first part of the workshop was planned for us to engage with some central texts featuring deconstruction (Caputo, 1997; Derrida, 1976; 2003; 2005; McQuillan, 2000; Spivak, 1976). When doing this work, we didn't want to treat deconstruction as an object of philosophical study in the way we usually tend to think about it. Rather, our intentions were, in line with Patti Lather's (2007) feminist thinking, to work ourselves 'away from abstract philosophizing and toward concrete efforts to put the theory to work' (p. 157). This meant that our main effort was not aimed at understanding the meanings produced by these texts from within their own contexts, although we of course discussed this as well in relation to what many of the secondary texts said about how to understand in what context Derrida's texts were written. Our main efforts were instead directed towards actively deconstructing our own 'take up' of the texts, in order to understand Derrida's challenge of our own metaphysical presuppositions and our own reactions to deconstruction. This work meant exposing ourselves to each other in ways that needed a lot of mutual acceptance and trust. This trust increasingly grew stronger from the feeling of inter-dependence in helping each other reveal some of the metaphysical presuppositions on which our thinking was based, in order to be able to displace it and make new meanings possible.

Before moving on to the second step of the workshop we worked out some routines for doing collaborative deconstructive analyses of our own data. At this point four of the initial fourteen participants chose not to partake in the next phase of the workshop for various reasons. The ten participants remaining agreed on a set of negotiated routines which I will discuss in more detail below. We had now reached a point where it didn't just feel necessary to put our dominant ways of thinking at 'risk', but where it also felt exciting and fun to do so, without knowing where this work might end up. We were now ready to know more about the processes by which we came to produce knowledge from our data the way we did, and foremost, we wanted to know if it was possible to understand it differently and otherwise (St. Pierre, 2000). As Patti Lather (2007: 105, italics added) has written, this was about 'a sort of getting lost as an ethical relationality of nonauthoritarian authority to what we know and how we know it'.

In feminist poststructural understandings of the processes of subjectification we become subjects in a simultaneous process of being subjected to dominant discourses and subjecting ourselves to them by picking up normalized meanings. Alternatively we might go against the grain of these meanings 
and formulate resistant meanings and discourses (Butler, 1997; Davies, 2000; Foucault, 1982). The subject can be understood as an individual patchwork or weave of materialized negotiated meanings (Butler, 1990; Davies, 2000). In such an understanding the researcher can only make meaning of her/his data by using the discursive tools available to her/him. We picked up the tools that lay most readily at hand, or to quote Judith Butler directly: 'There is only a taking up of the tools where they lie, where the very "taking up" is enabled by the tool lying there' (Butler, 1990: 145). As researchers we did this from within the scientific discourses and methodologies available to us in our field to make meaning of our empirical data (Davies \& Gannon, 2005). This constitutes a danger of a discursive closure (Derrida, 1976), which makes it difficult for us to think our data from within any other discourses than the ones available. Within the framework of this work-shop we wanted to challenge this risk of discursive closures and taken-for-granted presuppositions by engaging in collaborative work.

For the second part of the workshop our negotiated strategy was to analyse small pieces of our own and each other's data independently as a first step, and exchange these in the smaller group of 3-4 participants. Then, as a second step, we made deconstructive analysis of someone else's already written analysis of their data. All of these writings were exchanged over the internet and all participants had their own designs and layouts of deconstuctive writings. The third step was to meet monthly in the smaller groups of 3-4 persons to do collaborative deconstructive analyses for half the day. The group-work was based on all of the already generated deconstructive writings from 3-4 pieces of data. It was laid out on the table in front of us, in an unhierarchically, flattened out manner, to be further displaced and rethought. The second half of the day was spent in the larger group exchanging analyses across groups and discussing our ongoing processes and what they did to us and our analyses of the data.

We soon agreed that the most difficult kind of analysis was trying to, as a second step, displace and transgress your first preliminary reading of your own data. This was when the collaborativeness was particularly rewarding, as other participants from other fields of study (natural sciences, ethnography, social-work, education or political science) did readings of your data and your analysis. Their readings would often produce meaning in totally unexpected and subversive ways. It seemed easier to let go of your taken-for-granted assumptions, and disrupt and displace dominant and power-producing meaning-making when deconstructing someone else's data. Before I move on to discussing the ethics of these processes (Elam, 1994), I need to provide a lengthy discussion on how it is possible to at all understand deconstruction as an exorbitant methodological strategy.

\section{Deconstruction as an 'exorbitant' methodological strategy}

Martin McQuillan introduces his book Deconstruction: $A$ reader by reminding us that Derrida repeatedly stated that deconstruction is not a method. McQuillan writes that using a method means...:

... that we are going to follow a set of rules or fixed procedures, which if followed through will yield the desired result. /.../ There is no set of rules, no criteria, no procedure, no programme, no sequence of steps, no theory to be followed in deconstruction. (McQuillan, 2000, p. 3-4, original italics)

A method must have fixed procedures, rules and criteria; whereas doing and thinking methodologically, as I see it, does not necessarily do this. Poststructuralist theory has for a long time troubled the concept of method in the social and educational sciences, without giving up on doing something methodologically. Instead, methodologizing and theorizing your data is seen as an intimate relational process in much of feminist poststructuralist research (St. Pierre, 2000 Burman \& McLure, 2005; Davies, 2000; Davies \& Gannon, 2005; Lather, 1991; 2007; Lenz Taguchi, 2007; 2008; Rhedding-Jones, 2005). Erica Burman and Maggie MacLure (2005) explain why deconstruction cannot be seen as methodology as-usual, in their chapter called 'Deconstruction as a method of research' 
with a deconstructive strike-through in its title. If we talk of deconstruction as a method, we need to do so 'under erasure': This means that we need to deconstruct the taken-for-granted meanings of methodology, as well as continuously deconstruct the strategies we try out for doing deconstruction methodologically. They continue:

[T]o call it [deconstruction] a method or theory is to conjure another metaphysical opposition, between an external world and deconstruction, as if this were something separate which could be 'applied'. Deconstruction is always inextricably tangled up with whatever is its object. (Burman \& McLure, 2005: 286).

To understand this entangled relationship between deconstruction and its object, Derrida (1976) makes us aware of how our dominating Western logocentric thinking works. We tend to understand a word as carrying a meaning that corresponds to or directly represents a certain object or phenomenon existing prior to the concept. In Derrida's deconstructive thinking however, a concept is no longer understood as representing the world or carrying a meaning in itself. Rather, the meaning of a concept only becomes possible or evident in its relation to all other concepts we use and the meanings that are absent in the text. When we, in a feminist perspective, become aware of what is understood as a deviant or lacking human being (woman), the normal citizen is given its meaning (man) as presence and dominance (Burman \& Mac Lure, 2005; Davies \& Gannon, 2005; Elam, 1994). Our thinking is based on such binary oppositions as man/woman, mind/body, thinking/doing, where one word is prioritised and given a higher value, whereas the oppositional is considered minor with a lesser value. When reading deconstructively then, we search for and make visible the absent and discarded meanings, which in their absence give presence and dominance to the prioritised. Hence, deconstruction depends on what it deconstructs: It is a strategy that can only be done with and from within the set of meanings present in the text and the absences they rely on. This strategy of disruption and interference, with settled oppositions and dominant meanings, also aims to trace the limits and power-producing effects of these meanings and binaries. Deconstruction, writes James Williams (2005: 40) is constituted by a series of strategic ways of drawing out and subverting claims of truth in settled structures.

Derrida himself explicitly writes on the question of method under the heading of 'the Exorbitant' in Of Grammatology (1976). Here he discusses the impossibility to justify an absolute point of departure for determining (true) meaning, since our language can only offer us a trace of the original meaning (p. 162). Derrida writes that a deconstructive reading of a text 'must always aim at a certain relationship, unperceived by the writer, between what he commands and what he does not command of the patterns of the language that he uses' (p.158). The deconstructive reading must thus produce an imaginary gap or distance to the meanings in the text (the writer thinks that $s / h e$ ) is producing, to make visible the absent meanings. This is when supplementary readings can be produced. In Derrida's way of thinking, every meaning is a supplement to some other meaning, in an endless chain of signs. These indefinite multiplications of representation - these supplements - are 'quite exorbitant, in every sense of the word', writes Derrida (p. 163). They are about exorbitance and excess: one meaning always exceeding another.

When we produce such supplementary or multiple deconstructive readings, we should not think that they are produced by operating upon a text from the outside. Rather, they are always produced from within the indefinitely multiple meanings possible in the text of which we are always a part. Derrida (1976) writes that deconstruction cannot be applied as an independent tool from the outside to work on a text simply because 'there is nothing outside the text' (p. 163). And therefore '[w]e must begin wherever we are ... in the text where we already believe ourselves to be' (1976: 162, original italics). In stating this, Derrida acknowledges that we always read the text from our embeddedness in various networks of meaning - various horizons of presuppositions - which are social, historical, linguistic, political, sexual, gendered, etc. (Caputo, 1997: 79-80). However, deconstruction always involves the movement of trying to 'command of' what is being said in the text, from what we know of the social, 
historical, linguistic, political etc, presuppositions within which the text is written; although Caputo is critically aware of the impossibility of ever being able to fix or know these as true (p. 78).

As a methodological strategy then, we in our project first make a 'preparatory, preliminary, groundlaying, contextualizing reading', which is then followed by a 'fine-grained, distinctly deconstructive reading' (Caputo, 1997: 76). This second, third, and so on, deconstructive reading, make possible and visible the many (im)possible 'dangerous supplements' (Derrida, 1976: 159) that disrupt and subvert the dominant meaning and the oppositional logic on which they rely. Thus, when we engage ourselves in the movement of putting the sign and its meaning 'under erasure' (sous rature), other (im)possible readings can be made from the text (Spivak, 1976, in Derrida, 1976: xiv). However, as Spivak continues, the 'erasure' of the sign doesn't mean that the original meaning is erased, cast away or disposed of. Rather, it always remains legible/readable through the displaced reading in the movement of writing sous rature.

\section{'Deconstruction in a nutshell'}

To summarise the above, I want to turn again to John Caputo and his book Deconstruction in a Nutshell (1997). Here he uses the imagery of the nutshell to discuss deconstruction. The nutshell constitutes the Enlightenment idea of searching and finding the essentialism of things by gathering and researching for the probable by exclusion of the improbable, says Caputo. It is the Enlightenment Aufklärer's desire to explain the world by constructing truths or laws in the form of a nutshell. What deconstruction does, as I have tried to outline above, is instead an inclusion of the absent and improbable: to construct and invent new meanings. This movement is not about dismissing the dominant research paradigm, writes Caputo. Rather it is about becoming aware of and questioning the premises and the power-producing effects of the truths in such nutshells. Following Caputo, if science as-usual is constituting analyses as nutshells, '[o]ne might even say that cracking nutshells is what deconstruction is in a nutshell' (1997: 32). The exorbitance of deconstruction, writes Caputo, is about looking for the improbable, the unanticipated, the infinite; an inventionalism instead of an essentialism; a dissemination instead of a gathering; a deconstruction instead of a reconstruction (Caputo, 1997: 42).

In relation to using deconstruction as a methodological strategy then, deconstructive analysis can show in what ways the real, as we understand it, is constructed and what systems of discourse produce knowledge and power in certain ways (Davies and Gannon, 2005: 38). As such deconstruction means that the researcher must always, in what can be understood as a healthy selfsuspicion, deconstruct her own analysis as well. An important aspect of 'exorbitance' is thus the excessiveness and the feeling of the very high prize to pay when demanding of yourself to turn back on your own analysis over and over. To turn, bend and twist each meaning back on itself is a lengthy process we must undertake in order to identify how and why we do the kind of analysis we do: to find out on what presuppositions our analysis is made. This is when collaborative strategies can become very helpful.

\section{The collaborative strategy as an affirmative ethical activism and groundless solidarity}

In the process of doing collaborative analysis in a relatively large group of participants, over the relatively long time-period, the ethics of this work emerged while doing it. We negotiated the formalities and routines continuously and discussed the processes and what they did to us in e-mail conversations and process-documentation. We came to recognise the ethics of our process as an affirmative inter-dependence on each other's meaning-making. The persons 'behind' the words became of less and less interest to us. Rather, it was the feeling of interdependence on each other's readings that became invaluable in the process of making ourselves aware of our own discursive limitations when analysing our data. Moreover, the ease, creativity and, at times, excessiveness felt when deconstructing someone else's data, would slowly contaminate and transform the work we did on our own data. This helped disrupt taken-for-granted ways of thinking and opened up new 
possibilities. Derrida has said that deconstruction is much less about questioning and much more about affirmation (Derrida in Caputo, 1997). This is about an affirmative 'Yes, yes' of the other and the world that can be said to precede the questioning of it: an openness to the other before reason, says Derrida who continues

... the fact that deconstruction is 'yes,' is linked to the 'yes,' is an affirmation. /.../ I say

'yes' as a starting point. Nothing precedes the 'yes.' The 'yes' is the moment of

institution, of the origin; it is absolutely originary. (Derrida, 1997: 27)

A collaborative process practicing a strategy of disruption and displacement, requires of you a strong sense of responsibility in relation to the other. This is a responsibility of doing justice to the singularity of any kind of text or reading (Biesta, 2001: 37). 'Deconstruction is the haunting of the universal (such as law, rules, and knowledge) by the particular', writes Julian Edgoose (2001: 128). There can be no true or pure understanding or misunderstanding of a text. Rather, we need to take responsibility for the singularity of our analysis. This also means taking responsibility for the singularity in ourselves - in our own reading - as well as the singularity in the other's reading. Deconstruction involves an infinite responsibility beyond any theoretical certainty or determination (Derrida, 1996: 224). Thus, doing or 'applying deconstruction' means that you 'apply yourself', says Derrida (1996: 220).

This brings me to Diane Elam's (1994) understanding of how feminism and deconstruction merged together constitute an ethical activism and groundless solidarity. Ethical activism can never be about judging on the basis of a system of rules. Rather, this activism is about 'the search for the rule that may do justice to the case' (Elam, 1994: 198, italics added). This search for the singularity of the case is necessarily endless. This is because we can never know who a person 'is', be they woman, child or man. What we need to rely on is the possibility of a 'community as a whole of articulated singularities' (Elam, 1994: 109). It is the singularities in each of our readings, rather than in the number of separate bodies of participants in our group that constitutes such a community.

Moreover, neither these readings nor these participants can be grounded in essentialising identities and truths prior to language. Such a community constitutes the possibility for what Elam (1994: 109) calls 'groundless solidarity'.

The space that the ten PhD students and I created together during these seven months can be understood as having achieved such a community of articulated singularities in our process of doing collaborative deconstruction. Here it became possible to do justice to the multiplicity of not just the many different readings of data itself but also of the multiplicity of the subjects featuring the data, and of ourselves in our multiple subjectivities. With other words, this process was not about an intersubjective dialogue, where different subjects came to terms to achieve consensus and put an end to otherness. On the contrary, this is about an obligation to difference - the radical difference inbetween and within participants invoking singularities in our meaning-making (Elam, 1994: 110). Put more simply, this is about acknowledging the difference to the other (and the other in yourself), who does not choose the same thing or do the same reading for the same reasons you do. This is because we cannot know in advance the difference that a different reading might produce (Elam, 1994: 110).

When activating an ethical activism, we move away from rules and laws relying on fixed definitions and moral essences, and move towards an ethics where we try to make justice to the singularities of the case (Elam, 1994: 108). Justice, then, is the experience of undecidability, hesitation and doubt, in order to make possible for what might become, instead of knowing the truth or the law. 'Justice is beyond law', as Derrida says before he concludes: 'deconstruction is justice' (Derrida, 1990: 945, in Edgoose, 2001: 128). I will quote Derrida at length below as he discusses the relationship between law and justice, since in this quote he encapsulates - in a nutshell - what justice as deconstruction can be understood to be about. 
So, the law as such can be deconstructed and has to be deconstructed. That is the condition of historicity, revolution, morals ethics, and progress. But justice is not the law. Justice is what gives us the impulse, the drive, or the movement to improve the law, that is, to deconstruct the law. Without a call for justice we would not have any interest in deconstructing the law. That is why I said that the condition of possibility of deconstruction is a call for justice. /.../ You cannot calculate justice. Levinas says somewhere that the definition of justice - which is very minimal but which I love, which I think is really rigorous - is that justice is the relation to the other. That is all. Once you relate to the other as the other then something incalculable comes on the scene, something which cannot be reduced to the law or the history of legal structures. That is what gives deconstruction its movement, that is, constantly to suspect, to criticize the given determinations of culture, of institution, of legal systems, not in order to destroy them or simply to cancel them, but to be just with justice, to respect this relation to the other as justice (Derrida, 1997: 16-17).

Following from this, justice is incalculable. For us as researchers trying to 'do justice' in our research, this is as Patti Lather (2007: 105) so cleverly puts it, about 'getting lost as an ethical relationality' - an ethical relationality to the other, but also to ourselves and our data.

\section{The doing of deconstruction as an 'exorbitant' methodological strategy: an example}

This section starts with a piece of interview-data with a six-year-old boy who is considered by the teachers at his school to have 'special needs'. The focus of the interview is on what happened the day before the interview, as the whole class went to the river to make bark-boats. The interviewer wants the boy to talk freely on the topic of what happened, in order to find out more about how he constructs himself as a schoolboy.

Interviewer: OK. Here I sit with you $\mathrm{E}$ and a while ago I sat here with $\mathrm{M}$. How are you feeling?

'Erik': I am OK.

I: Do you like being interviewed?

E: Yes, a little.

I: Today I was thinking we should just talk for a little while. And you will decide what we should talk about, but I have a question for you, since I wasn't here yesterday. I missed out on that day because I had other things to do. How was yesterday? What happened?

E: Well, it was... [An adult walks by to get something. E stops talking. He snuffles, is quiet for a while and then starts talking with a weak voice.]

I: What did you say?

E: It was good.

I: What was good?

E: [Somewhat irritated] The whole day was good.

I: You made boats out of bark from a tree?

E: Hmm.

I: Did you have fun?

E: Yes, I did.

I: Did you get to carve the boat yourself?

E: Yes, we did.

I: And then you put them into the water?

[E seems embarrassed.]

E: Hmm.

I: Did you have a competition?

E: Hmm. But my boat sank. It jumped... and landed up side down.

I: So, you had...

Reconceptualizing Educational Research Methodology 2010, 1(1)

http://www.rerm.hio.no 
E: I did a rather nice funeral for it, cause $\mathrm{S}$ threw flowers on the boat.

I: So it sank or did it turn over first?

E: OK listen! [In a strong voice, and then successively lowering it.] It turned over and I had made a man sitting on it who died, and it floated up side down... S threw flowers so it turned out well [the last sentence is almost inaudible]

I: What did you do then?

E: I went away and shouted [changes his voice to a louder pitch] "Leave the ship, the boat is sinking!" I said and went away.

I: So, you didn't turn angry?

E: No. [With a firm voice]

The interviewer offered her data for us to help her read the data differently. In her own initial analysis she had focussed on some of the expressions and words used by the boy such as: 'the whole day', to 'sink' and be 'upside down'. They signal to her that the boy struggles with himself and with his relationships to his class-mates in a situation of defeat, as the boat turns up side down and sinks. She made a note of the boy not being entirely 'truthful' in what he is saying, based on what she knows about him from previous observations. In her analysis, she writes that she thinks that although 'Erik' tries 'to be something he is not', he manages to turn 'his disappointment into something good' when he accepts help from his friend $(\mathrm{S})$ and shows trust in her during the interview. She concluded her analysis in the following way:

E struggles with himself and his difficulties to be in a good relationship with the children around him. He has difficulties in handling his subjectivity as a good school boy, which is of course the dominating idea in school. S [the girl] in this context is supporting the boy and helps him overcome his defeat. /... E accepts $\mathrm{S}$ support which is a step in the right direction for him, but he is still unsure of $S$ being a friend.

What the PhD student does when she produces this first reading, which Caputo (1997: 76) would have called the first "preparatory, preliminary, ground-laying, contextualising", is that she reads the interview transcript from within the taken-for-granted notions in the school context, in which she is embedded. It is, however, her awareness of this that makes her bring this piece of data to the collaborative process of deconstruction. When other participants deconstructed the data as well as the first initial reading, it was revealed that any 'innocent' reading or analysis of data is always already based on theoretical presuppositions (Davies and Gannon, 2005). Informed by discourses of developmental psychology and her education as teacher, the PhD student already had a theoretically informed belief of this child's problems in constituting himself as a school-boy. This reading constituted (Caputo, 1997) the 'nutshell' to be cracked open. The cracking-open happened when different readings were put side by side in an unhierarchical fashion during the collaborative deconstructive process.

One of the deconstructive readings offered by a participant in the group simply focussed on the absences and what was not in the data and the initial analysis of it. This made visible the (im)possible reading of the boy as a self-reliant and trustworthy boy, instead of being understood as unsure and lacking in truthfulness and sociability. In such a reading, this boy can instead be understood as sure of himself, using an increasingly stronger voice, and saying that what he believes is true. He can be understood as having a healthy mistrust in relation to the adults in school. Moreover, he can be understood to manage quite well with little support from others. When victorious, he shows no feelings. When in defeat he is not disappointed. In producing meaning from the interview-data in this way, by putting the data and the initial analysis 'under erasure', it became obvious to us that there is actually nothing in the transcript that indicates that we could not understand the boy in accordance with this reversal reading of him as self-reliant and trustworthy. Laying the first reading and this second reading beside each other, on the table, constituted an almost brutal awakening to some of 
the participants, especially to those who were deeply inscribed in the developmental psychological discourses from various undergraduate studies.

During the collaborative deconstructive talks in the group we identified numerous questions on the boy's 'behaviour' and expression of feelings. This was important, since it was from these behaviours and expressions that he was judged as being a 'good' school-boy or not. In a deconstructive reading of the interview, it is possible to see how the interviewer is unconsciously positioning herself as a representative for the constitutive powers of the school-boy's adequate and correct subjectivity construction. However, when looking more closely at what the boy says and doesn't say, and how he says what he says, a strong power-production towards the interviewer also becomes visible. Although he is subjected to this power-producing situation and producing many hesitant answers, these sometimes inaudible answers can also be read as a powerful resistance. It is when resistance is made visible that we know a subjecting power-production is going on (Foucault, 1982). Hence, as the interview continues, the boy answers with a stronger and stronger voice; perhaps with resistance. He tries to explain what he means. He interrupts the interviewer once, and shortly afterwards explicitly and irritatingly exclaims: 'OK listen!' Afterwards 'he changes his voice to a louder pitch' (as the transcript reveals) and answers the last key-question about whether he had turned angry or not with a firm 'No'. Thus, he can be understood as quite successful in resisting the power production at work in the interview. This would become even more apparent if we imagine the boy to be a girl. From a feminist perspective, the boy's resistant strategies, encompassing insufficient or unelaborated answers, and later turning into strong voiced exclamations such as 'OK listen!' and providing a firm 'No', would probably have been read as far more aggressive and resistant had the child been a girl (Davies, 2000; Walkerdine, 1990, 1998). What can be understood as rightfully powerful boyish or masculine behaviour with a culturally and ethnic Swedish boy might have been understood as totally deficient behaviour with a girl, or with a boy of another cultural or ethnic background than Swedish, or perhaps of a lower class position, or any combinations of these (Lykke, 2003).

The deconstructive reading, that more than any of the other readings made us feel that we transgressed the limits of discourse, was a reading of the interview situation itself. One of the participants asked herself how the performance of the interview was actively producing power in relation to how the boy constructed himself as a school-boy. With other words, the reading questioned how the research methodology, in the singularity of this interview situation, produced the same phenomena as it had set out to study. This reading dislocated and disrupted our understanding of the whole situation, and put us at the limit of research methodology. The question that emerged was: How does this specific conversation between Erik and the interviewer discursively constitute and materialise him as a school-boy? How does the boy pick up the interviewer's ideas about what it is to be a good school-boy in a correct manner from within the materialisation of the interview situation itself? The analysis below was performed on a short descriptive text supplied together with the transcript of the interview above. First is the descriptive text, and then follows the deconstructive analysis based on this text and parts of the interview. Italics here represent what we later saw as focal points in the analysis.

I sit in a room with $\mathrm{E}$ who is a pupil in the pre-school class in this school. The pre-school class is small, five girls and three boys and I have conversations with one child at the time. It's the end of May and the previous day the children had been by the river with their teacher and an elderly lady from the village. They made boats out of bark from a tree. I chose not to be present that day. My intention is to hear what the children have to tell from the day at the river, to be able to know more about what the children find interesting in this particular situation. My eyes are focussed on how children construct themselves and are constructed by the environment as pupils, and how they master and subordinate themselves as pupils. 
As a basis of her analysis the collaborative participant has constructed temporary binary pairs in order for us to focus on the absent meanings that produce those present. Here the uses of bold, underlining, erasure, inverted commas, capital letters, brackets and central formatting all served various purposes for those doing the analysis.

\author{
INTERVIEW \\ "in a room" (APPROPRIATE PLACE) - anywhere (ANY \& DIFFERENT PLACES) \\ "one child at the time" (EACH CHILD'S VOICE) - all at once (CO-CONSTRUCTION) \\ "hear what the children have to tell" (ANYTHING) - ask of specific things (SPECIFIC INFO) \\ "what the children find interesting" (INTERESTING) - what did not happen that day/ what was trivial \\ (TRIVIAL) \\ From the interview excerpt \\ "do you like being interviewed?" (FORMAL) - talk freely and randomly (INFORMAL) \\ "should just talk for a little while" (LIMITED TIME) - talk without decided time (UNLIMITED) \\ "you will decide" - the researcher decides \\ (QUESTIONS): “what?” “how?” “what was?” “did you?” “you made?” - free, interactive talk (NO \\ QUESTIONS)
}

What can be understood as the excluded discourse on interviewing can be read from the words on the right hand side of the binaries. This is what was not taking place; that is, an informal talk, at any possible and comfortable place, with several children co-constructing meaning around anything that they find interesting, under unlimited time conditions where the grown up person is not asking any specific questions. What, however, seems to have taken place is that the researcher seems to know what she wants to have information about, and she keeps on asking questions about that. The boy can be understood to read the situation and answer in accordance with what he thinks is expected of him. He might be well aware of that the adults want him to have 'good days': that is, to behave well, to take his defeats with good temper, and to get along well with other children. He explicitly comments on the whole situation that his friend 'threw flowers [on the sinking boat] so it turned out well'. Thus he answers the questions dutifully and according with what he thinks is expected from him. Although he might not fully succeed in this, what is important is that he is trying his best to actually perform being a 'good school-boy' in this interview situation. That is the boy that he knows that everyone wants him to become.

So in spite of the explicit idea of letting children talk with the researcher in a more informal manner, for them to reveal 'how they construct themselves and are constructed by the environment as pupils, and how they master and subordinate themselves as pupils', this deconstructive reading, based on the temporary construction of binaries above, suggests that a quite formal interview discourse and practice are dominating the situation. The innocent idea about being able to talk to children in order to get hold of and understand how they 'master and subordinate themselves' might be understood as in itself a subordinating situation for a child. Moreover, the researcher subordinates herself in relation to a dominant interview discourse and practice. The talk turns out to end up in a significant pattern of: I ask questions - you answer, in spite of the explicit intention that the boy should decide himself upon what to tell from what happened the day before. The central question here, for researchers wanting to study how children constitute their subjectivities as schoolchildren, is how they can distinguish a researcher from any other adult in the school. The critical issue regards who repeatedly puts them in interview-like situations to check or diagnose their behaviour and learning.

\title{
Concluding discussion
}

Sometimes we are so deeply embedded and inscribed in the dominant discourses of our own research field as qualitative researchers, that everything we think we can see in the data is what we already know. The example in this paper shows how doing collaborative deconstructive analysis on each other's data makes visible a most important aspect of deconstruction. This is not simply 
identifying taken-for-granted meaning-making, but is instead about displacing and making other readings possible. In this way we might, as Caputo (1997: 81) says, cross 'a well-drawn border that we all share, giving something straight a new bent or inclination or twist'. As a result of this process it was no longer possible to simply understand the boy in the interview as lacking in truthfulness or being unsure, although this is the reading of the data which seems to lie most readily at hand. On the other hand it was equally impossible to understand him as unproblematically powerful and competent when reading the data from the absent meanings. Doing multiple readings from the thickness and multiplicities of an event makes it possible for us to understand this boy, not in essentialising and polarized terms as either this or that, but as multiple. That is, he becomes different to himself and others, understood sometimes in shifting and contradictory terms, when being positioned and positioning himself differently in the different events of making a bark-boat that turns over and sinks, and doing an interview with a teacher who is also a researcher. This makes it possible to, as Gregory Ulmer (1985: 5, italics added) writes, understand deconstruction as 'a mode of writing and ultimately a pedagogical practice /.../ designed to overcome the logocentric limitations of discourse'.

Our strategy in doing deconstruction as such a pedagogical practice was 'getting lost' together, and trying to keep open, alive and loose, whilst on guard against ourselves, as Lather says (2007: 105). In this way we were able to think the unthinkable in relation to our data. This is something very different from 'gathering evidence' that points to a possible truth embedded in the data. Lather also writes that deconstruction is not about denying reality or reference, but a strategy of complicating it (Lather, 2007: 157). Our collaborative readings indeed complicated our understandings of the data to the extent that we questioned the interview methodology itself now seeing this as a producer of oppressive power production, producing exactly that which the research had set out to study. Thinking in such completely new and unthinkable ways involves what Caputo (1997) refers to as a quality of deconstruction as inventionalism. Does such inventionalism however make it possible for us to do better justice to our qualitative research data?

Our feeling was that this collaborative strategy actually did better justice to previously unthought potentialities of the data in our multiple analyses of it. After this work it became virtually impossible for the research student, who produced this particular data, to not include analysis of how her interviewing became part of constituting children's subjectivities in the study. However, we also learned that no ultimately just reading of data is possible. Although the dissemination and unhierarchical spreading and flattening out of our analysis made us aware of the many layers and the thickness of an event, it also made us aware of the limitations of discourse, and what is possible to know from different discourses and discursive positionings. Lather (2007) writes that having worked the tension between explanation and understanding in qualitative research during the last decade, she has come to understand that if subjects are not transparent to themselves there is an inevitable limit to our competence and ability to give meaning to our lives and our research. Moreover, given the indeterminacies of language and the workings of power in 'the will to know', perhaps we need to submit to an understanding of both ourselves as researchers and the researched in our data as 'unreliable narrators' (Lather, 2007: 158). Maybe the closest we can come to 'doing just readings' of data is thinking that deconstruction itself is justice, as Derrida suggests (Derrida, 1990: 945, in Edgoose, 2001: 128). However, working at the limits of discourse, we become aware of the limits of deconstruction at the same time, writes Lather, as she wonders where to go next in terms of methodology for qualitative research (2007: 158).

To conclude: While I claim that the collaborative work that we performed contests the requests of certainty of research outputs and measures that, as Cheek states (2007) are currently working us over, I am perfectly aware that those who question the efficacy of qualitative research would gladly work the contents and conclusions of this article over without mercy. In fact, they would probably claim this paper to be the perfect piece of evidence needed for why we need to apply principles of 
positivism to our research. Deconstruction can, of course, never be a straight forward positive science, as James Williams writes (2005). To involve yourself in deconstruction is an investigation in the impossibilities of finding true meanings outside of historical contexts and social practices. Moreover, it means investigating the consequences for research of this impossibility of a truth prior to or separated from our meaning-making in language. Science cannot take place in a vacuum, apart from historical, practical, economic and social presuppositions (Williams, 2005: 46). The role of deconstruction is to think beyond the limits of the truth-claims produced as positive evidence, using objective methods and neutral theories. Therefore deconstruction is not about being opposed to science. Rather, it is to be deeply involved with not just positivist science, but any kind of practice claiming to produce knowledge (Williams, 2005: 47). This also means that the consequence for research claiming to do deconstructive research is that it too needs to deconstruct its own production of meaning, over and over.

Maybe what we can learn from this collaborative process of deconstruction as an 'exorbitant' strategy is that we need to make ourselves aware, both of our discursive limitations, and of the limitations of our own methodologies. This way we will not let ourselves be 'worked over', as Cheek (2007) warns us, neither by the contemporary demands of evidence-based research methodologies in the space of academia at large, nor by our own methodologies in our own spaces of qualitative research. Deconstruction as an 'exorbitant' strategy can perhaps provide us with the necessary 'hesitation' (Cheek, 2007) we need in our self-critical activism as qualitative researchers.

\section{Acknowledgements}

I am indebted to the ten participants who followed the full seven months of this course-work, and who gave their consent to anyone in the group to use the collectively produced documentation, analyses and e-mail conversations to write papers or articles on. In alphabetical order: Camilla Eline Andersen, Auli Arvola-Orlander, Ingela Elfström, Bodil Halvars-Franzén, Gudrun Alda Hardardóttir, Karin Hultman, lann Lundeborg, Lottie Nyfors-Nyblom, Anna Palmer and Hanna Wikström. I am also greatful for important and constructive feedback from the referees of this paper.

\section{References}

Biesta, G. J. J. (2001) Preparing for the incalculable: deconstruction, justice, and the question of education. In G. J. J. and D. Egéa-Kuehne (eds) Derrida and Education. Oxon and New York: Routledge.

Burman, E. \& MacLure, M. (2005) Deconstruction as a method of research. In B. Somekh and C. Lewin (eds) Research Methods in the Social Sciences. London, Thousand Oaks and New Delhi: Sage Publications.

Butler, J. (1990) Gender Trouble: Feminism and the subversion of identity. New York and London: Routledge.

Butler, J. (1997) The Psychic Life of Power: Theories in subjection. Stanford: Stanford University Press.

Caputo, J. (ed.) (1997) Deconstruction in a Nutshell: A conversation with Jacques Derrida. New York: Fordham University Press.

Cheek, J. (2007) Qualitative inquiry, ethics, and politics of evidence: working within these spaces rather than being worked over by them, Qualitative Inquiry 13(8): 1051-1059.

Davies, B. (2000) A Body of Writing 1990-1999. Walnut Creek, Ca. and Oxford: Alta MiraPress.

Davies, B. \& Gannon, S. (2005) Feminism/Poststructuralism. In B. Somekh and C. Lewin (eds) Research Methods in the Social Sciences. London, Thousand Oaks and New Delhi: Sage Publications, pp. 318-325.

Derrida, J. (1976) Of Grammatology. Baltimore and London: The John Hopkins University Press.

Derrida, J. (1996) 'As if I were dead: an interview with Jacques Derrida. In J. Branningan, R. Robbins and J. Wolfreys (eds) Applying: To Derrida. Hampshire and London: MacMillan Press. 
Derrida, J. (1997) The Villanova roundtable: a conversation with Jacques Derrida. In J. Caputo (ed.) Deconstruction in a Nutshell: A conversation with Jacques Derrida. New York: Fordham University Press.

Derrida, J. (2003) Following Theory. In M. Payne and J. Schad (eds.) Life.after.theory. London and New York: Continuum.

Derrida, J. (2005) Lagens kraft [The force of Law 1994]. Stockholm: Symposion.

Edgoose, J. (2001) Just decide! Derrida and the ethical apriorias of education. In G. J.

J. Biesta and D. Egéa-Kuehne (eds) Derrida and Education. Oxon and New York: Routledge, pp. 119-133.

Elam, D. (1994) Feminism and Deconstruction. Ms. En Abyme. London and New York: Routledge.

Foucault, M. (1982) The subject and power. In H. L., Dreyfus and P. Rabinow (ed.) Michel Foucault: Beyond structuralism and hermeneutics. Hertfordshire: The Harvester Press, pp. 208-228.

Lather, P. (1991) Getting Smart: Feminist research and pedagogy with/in the postmodern. New York and London: Routledge.

Lather, P. (2007) Getting Lost: Feminist efforts toward a double(d) science. New York: State University of New York Press.

Lenz Taguchi, H. (2007) Deconstructing and transgressing the theory-practice dichotomy in Swedish early childhood education. Educational Philosophy and Theory, 39(3): 275-290.

Lenz Taguchi, H. (2008) An 'ethics of resistance' challenges taken-for-granted ideas in early childhood education. International Journal of Educational Research, 47 (5) : 270-282.

Lykke, N. (2003) Intersektionalitet -ett användbart begrepp för genusforskningen [Intersectionality: a useful concept in gender-studies] Kvinnovetenskaplig tidskrift [Journal of Women's Studies] (1): 47-56.

McQuillan, M. (2000) Deconstruction: A reader. Edinburgh: Edinburgh University Press.

Rhedding-Jones, J. (2005) What is Research? Methodological practices and new approaches. Oslo: Universitetsforlaget.

Spivak, G. C. (1976) Translator's preface. In J. Derrida, Of Grammatology. Baltimore and London: The Johns Hopkins University Press, pp. ix-Ixxxiv.

St. Pierre, E. A. (2000) Poststructural feminism in education: An overview, Qualitative Studies in Education 14(1): 71-84.

Ulmer, G. L. (1985) Applied Grammatology: Post(e)-Pedagogy from Jacques Derrida to Juseph Beuys. Baltimore and London: The Johns Hopkins University Press.

Walkerdine, V. (1998) Counting Girls Out: Girls and mathematics. London: Falmer Press.

Walkerdine, V. (1990) Schoolgirl Fictions. London: Verso.

Williams, J. (2005) Understanding Poststructuralism. Stocksfield UK: Acumen Publishing Limited.

\footnotetext{
${ }^{\mathrm{i}}$ The twelve PhD students represented different academic fields and came from different universities; educational didactics of science; feminist poststructural child- and youth-studies, early childhood education and special education within the educational field, as well as social work, ethnography and political science.
} 